\title{
BEBAN KERJA MENTAL, FISIK DAN WAKTU PERAWAT DI POLI RSUD dr. SLAMET GARUT
}

\author{
Egis Permana ${ }^{1)}$, Ati Surya Mediawati ${ }^{2)}$, Indra Maulana ${ }^{3)}$ \\ ${ }^{1}$ Universitas Padjadjaran \\ e-mail: indra.maulana@unpad.ac.id
}

\begin{abstract}
ABSTRAK
Beban kerja mental merupakan suatu perbedaan antara kapasitas dan kemampuan dalam melakukan pekerjaan atau tugas-tugasnya. Beban kerja yang tinggi bisa menyebabkan beban kerja mental, fisik, dan waktu sedangkan beban kerja yang rendah bisa menyebabkan kebosanan dan kejenuhan. Tujuan penelitian ini untuk mengetahui gambaran beban kerja mental, fisik, dan waktu perawat di ruangan poli RSU dr, Slamet Garut. Metode Penelitian ini menggunakan deskriptif kuantitatif, Populasi penelitian ini adalah seluruh perawat di ruangan poli RSU dr Slamet Garut. Teknik pengambilan sampel total sampling, dengan besar sampel yaitu 62 orang perawat. Pengukuran beban kerja mental menggunakan NASA TLX yang dinilai oleh peneliti dari lembar kuesioner. Analisis data menggunakan analisis deskritif kuantitatif. Hasil penelitian menunjukkan beban kerja mental kategori tinggi sebanyak 58 responden $(100,0 \%)$, beban kerja fisik kategori tinggi sebanyak 57 responden $(98,3 \%)$, dan beban kerja waktu kategori tinggi sebanyak 57 responden $(98,3 \%)$. Kesimpulan penelitian ini menggambarkan bahwa beban kerja perawat di ruangan poli RSU dr Slamet Garut kategori tinggi baik beban kerja mental, fisik, dan waktu. Perlunya perbaikan manajemen keperawatan perawat perlu menjaga kondisi fisik dan mental dalam memberikan pelayanan keperawatan karena beban kerja yang tinggi
\end{abstract}

Kata kunci: Beban Kerja Mental, Beban Kerja Fisik, Beban Kerja Waktu

\begin{abstract}
Mental workload is a difference between capacity and ability to do work or tasks. High workload can cause mental workload, physical, time and low workload can cause boredom and burnout. This study is to find out how the mental, physical and nurse workload depictions in the poly room of dr. Slamet Garut Hospital. The research method used quantitative descriptive design. The population of the study was all nurses in the poly room of dr. Slamet Garut Hospital. The sampling technique was total sampling, with 62 nurses. The measurement of mental workload using NASA TLX which was assessed by researchers from the questionnaire sheet. The data analysis used quantitative descriptive analysis. The results showed that mental workload in the high category was 58 respondents (100.0\%), physical workload in the high category was 57 respondents (98.3\%), and the time workload in the high category was 57 respondents (98.3\%). The conclusion was the workload of nurses in the poly room of dr. Slamet Garut Hospital in a high category both mental, physical, and time workloads. There needs to be an improvement in nursing management and nurses need to maintain physical and mental conditions in providing nursing services because of high workloads
\end{abstract}

Keywords: Mental Workload, Physical Workload, Time Workload 


\section{PENDAhUluan}

$\begin{array}{ccc}\text { Rumah } & \text { sakit adalah salah satu } \\ \text { sarana } & \text { kesehatan } & \text { yang }\end{array}$ menyelenggarakan kegiatan kesehatan untuk memelihara dan meningkatkan kesehatan serta bertujuan untuk mewujudkan derajat kesehatan yang optimal bagi masyarakat. Upaya kesehatan dilakukan dengan pendekatan pemeliharaan, peningkatan kesehatan (promotif), pencegahan penyakit (preventif), penyembuhan penyakit (kuratif), dan pemulihan (rehabilitatif) yang dilaksanakan secara serasi dan terpadu serta berkesinambungan. Menurut UU RI Nomor 44 Tahun 2009 tentang rumah sakit, rumah sakit adalah institusi pelayanan kesehatan yang menyelenggarakan pelayanan kesehatan perorangan secara paripurna yang menyediakan pelayanan rawat inap, rawat jalan, dan gawat darurat.

Pelayanan di rumah sakit merupakan organisasi yang bergerak dalam bidang jasa, pada kondisi tersebut para manajer rumah sakit dan manajer sumber daya manusia yang ada di dalamnya dituntut untuk mengelolanya secara baik, dan diperlukan juga tenaga kesehatan yang handal, salah satunya adalah tenaga keperawatan. Tenaga keperawatan merupakan salah satu jenis tenaga kesehatan yang diperlukan agar pelayanan di rumah sakit bisa berjalan. Oleh sebab itu keperawatan di rumah sakit harus diperhatikan pengelolaannya agar dapat memenuhi tuntutan pasien yang semakin tinggi Keberhasilan dari rumah sakit dalam menjalankan setiap perannya dapat dilihat dengan pelayanan mutu (Purba, 2018).

Pelayanan rawat jalan adalah satu bentuk dari pelayanan kedokteran. Secara sederhana yang dimaksud dengan pelayanan rawat jalan adalah pelayanan kedokteran yang disediakan untuk pasien tidak dalam bentuk rawat inap (hospitalization). Pelayanan rawat jalan ini termasuk tidak hanya yang diselenggarakan oleh sarana pelayanan kesehatan yang telah lazim dikenal rumah sakit atau klinik, tetapi juga yang diselenggarakan di rumah pasien (home care) serta di rumah perawatan (nursing homes). Rawat jalan adalah pelayanan kepada seorang pasien untuk tujuan pengamatan, diagnosis, pengobatan, rehabilitasi, dan pelayanan kesehatan lainnya, tanpa mengharuskan pasien tersebut dirawat inap. Tujuan dari pelayanan rawat jalan adalah mengupayakan kesembuhan dan pemulihan pasien secara optimal melalui prosedur dan tindakan yang dapat dipertanggung jawabkan. Sedangkan fungsi dari pelayanan rawat jalan adalah sebagai tempat konsultasi, penyelidikan, pemeriksaan dan pengobatan pasien oleh dokter ahli dibidangnya masingmasing yang disediakan untuk pasien yang membutuhkan waktu singkat untuk penyembuhannya atau tidak memerlukan pelayanan perawatan.

Menurut WHO (2011), ditemukan fakta bahwa perawat yang bekerja di rumah sakit di Indonesia mengalami peningkatan beban kerja masih mengalami kekurangan jumlah perawat. Hal ini disebabkan karena peran perawat belum didefinisikan dengan baik, keterampilan perawat masih kurang dan kebanyakan perawat diberikan tugas-tugas non keperawatan. Beberapa penelitian di temukan bahwa stres kerja merupakan hal lazim bagi perawat, salah satunya disebabkan

beban kerja mental perawat yang tingg i,

apabila perawat memiliki tingkat stress yang tinggi akan menurunkan kinerja $\mathrm{p}$ erawat (Kalendesag \& Malara, 2017).

Selain memiliki peran, perawat juga memiliki 3 fungsi diantaranya fungsi independen, interdependen dan dependen. Fungsi independen yaitu 
tindakan yang dilakukan bersifat mandiri, berdasarkan ilmu dan kiat keperawatan. Pada fungsi interpenden, tindakan perawat berdasarkan pada kerjasama dengan tim perawatan atau tim kesehatan lain. Sedangkan pada fungsi dependen perawat bertindak membantu dokter dalam memberikan pelayanan medik.

Peneliti melakukan studi pendahuluan pelayanan di Poli RSUD dr. Slamet Garut. Berdasarkan hasil studi pendahuluan diketahui bahwa pemberian nomor antrian kurang efektif karena masih banyak pasien yang menumpuk di ruang tunggu. Tindakan lain dari pelayanan keperawatan yang dilakukan di unit rawat jalan antara lain sebagai memanggil pasien yang akan dilakukan pemeriksaan, melakukan kajian awal klinis bagi pasien baru yang belum pernah dilakukan kajian awal. Melakukan anamnesa, pemeriksaan, mengukur tanda-tanda vital pasien, membantu tenaga medis melakukan tindakan ke pasien, memberikan resep yang telah di tuliskan dokter dan melakukan perawatan luka, penyuluhan tentang penyakit dan pola hidup sehat. Analisis penyebab dari permasalahan nomor antrian yang kurang efektif, pasien yang mendapat pelayanan telebih dahulu adalah keterambatan pelayanan tindakan dan kehadiran tim kesehatan yang tidak semestinya membuat perawat yang ada diruang pasien mendapat banyak tekanan dari pesien dan keluarga karena kekesalan pasien yang semakin menumpuk.

Keadaan ini ditambah dengan Kinerja dikatakan tinggi apabila suatu target kerja dapat diselesaikan pada waktu yang tepat atau tidak melampaui batas waktu yang disediakan sedangkan kinerja dikatakan rendah jika diselesaikan melampaui batas waktu yang disediakan atau sama sekali tidak terselesaikan (Manuho, Warouw \& Hamel, 2015).

Dengan waktu yang sering melewati batas dalam melakukan pekerjaannya seorang perawat akan rentan bagi seorang perawat terkena stress dalam melakukan pekerjaannya.

Hasil dari studi pendahuluan pada Maret 2019, di RSUD dr. Slamet Garut jumlah kunjungan pasien rawat jalan mengalami peningkatan setiap bulannya, walaupun mengalami penurunan di bulan Mei, Fenomena ini dapat diartikan sebagaimana beban kerja dari bulan ke bulan semakin tinggi, dan terdapat 58 orang perawat di poli RSUD dr. Slamet Garut, artinya jumlah perawat yang terbatas yang memungkinkan pembagian waktu, beban kerja mental dan fisik perawat akan lebih banyak. Menangani 16,5605 orang pasien selama tahun 2018. Sedangkan perhari mencapai 170 pasien di poli, dan terdapat 17 ruangan di Poli RSUD dr. Slamet Garut. Berdasarkan hasil wawancarai diketahui terdapat 58 perawat di Poli. Pada data absensi perawat terdapat 5 orang perawat yang tidak hadir dengan alasan sakit, 2 orang cuti bergantian, perawat yang izin sebanyak 3 orang. Hal tersebut tentunya akan mempengaruhi perawat yang lain dan akan menimbulkan beban serta kelelahan dalam bekerja.

\section{PELAKSANAAN}

a. Lokasi dan Waktu Penelitian

Penelitian ini mengambil tempat yakni di RSU dr Slamet Garut Kabupaten Garut Pengambilan data dilakukan pada bulan July 2019.

b. Populasi dan Sampel Penelitian Populasi penelitian ini adalah perawat di ruangan Poli RSUD dr. Slamet Garut yang terdiri 58 orang perawat. Teknik pengambilan sampel yaitu dengan cara total sampling. Responden 
yang dijadikan sampel adalah semua perawat yang ada di poli RSUD Dr, Slamet Garut. Peneliti mendapatkan sampel 58 responden dalam penelitian ini.

\section{METODE PENELITIAN}

Jenis penelitian yang digunakan adalah deskriptif dengan menggunakan pendekatan kuantitatif. Instrumen yang di gunakan NASA TLX yang mencakup beban kerja mental, fisik, waktu perawat di ruangan RSUD dr. Slamet Garut. NASA-TLX (National Aeronrutics and Space AdministrationTask Load index) dikembangkan oleh Sandra dari NASA-Ames Research Center dan Lowell E. Staveland dari San Jose State University pada tahun 1981. Metode ini dikembangkan berdasarkan munculnya kebutuhan pengukuran subjektif yang terdiri dari skala sembilan faktor (kesulitan kerja, tekanan waktu, jenis aktivitas, upaya fisik, upaya mental, performansi, frustasi, stres, dan kelelahan).

Metode analisis yang digunakan adalah metode analisis deskriptif dan kuantitatif. Interpestasi hasil nilai skor untuk mendapatkan nilai skor beban mental NASA-TLX, bobot dan rating untuk setiap indikator dikalikan dan dijumlahkan 15 (jumlah perbandingan berpasangan). Skor beban kerja yang diperoleh dapat diintepretasikan yaitu nilai skor 0 s/d 50 menyatakan beban kerja rendah, nilai skor 51 s/d 100 menyatakan beban kerja sangat tinggi dan nilai skor NASA-TLX untuk mendapatkan nilai skor beban mental NASA-TLX, bobot dan rating untuk setiap indikator yang digunakan disebut adjusted rating kemudian dijumlahkan dan dibagi 15 (jumlah perbandingan berpasangan)

\section{HASIL DAN PEMBAHASAN}

Hasil penelitian dan pembahasan tentang gambaran beban kerja mental, fisik dan waktu perawat di poli RSUD dr. Slamet Garut. Penelitian ini di mulai pada tanggal 15-29 Juli 2019, langkah awal yang dilakukan yaitu melakukan informed consent, persetujuan menjadi responden, kemudian peneliti membagikan kuisioner. Hasil penelitian disajikan dalam bentuk tabel yang menggambarkan distribusi tentang beban kerja perawat baik mental, fisik, dan waktunya.

Tabel dibawah ini menjelaskan beban kerja mental, fisik dan waktu perawat berdasarkan domain

Tabel 1 Distribusi Ferkuensi Beban Kerja Mental, Fisik dan Waktu Perawat di Poli RSUD dr. Slamet Garut $(n=58)$

\begin{tabular}{lcccc}
\hline Beban & \multicolumn{2}{c}{ Rendah } & \multicolumn{2}{c}{ Tinggi } \\
\cline { 2 - 5 } Kerja & $(\mathbf{F})$ & $\mathbf{( \% )}$ & $\mathbf{( F )}$ & $\mathbf{( \% )}$ \\
\hline Mental & 0 & 0,0 & 58 & 100,0 \\
Fisik & 1 & 1,7 & 57 & 98,3 \\
Waktu & 1 & 1,7 & 57 & 98,3 \\
\hline
\end{tabular}

Berdasarkan tabel 2 didapatkan hasil bahwa seluruh responden berada pada kategori mental tinggi yaitu sebanyak 58 responden $(100,0 \%)$, pada kategori fisik mendominasi hasil tinggi sebanyak 57 responden $(98,3 \%)$ dan sebagian kecil responden dengan hasil rendah sebanyak 1 responden $(1,7 \%)$. Pada kategori waktu mendominasi dengan hasil tinggi sebanyak 57 responden $(98,3 \%)$ serta yang memiliki persentasi rendah sebanyak 1 responden $(1,7 \%)$

Berikut ini akan dijelaskan mengenai beban kerja mental, fisik dan waktu perawat di Poli RSUD dr. Slamet Garut secara keseluruhan.

Tabel 2 Distribusi Frekuensi Berdasarkan Beban Kerja Perawat Secara Keseluruhan $(\mathrm{n}=58)$.

\begin{tabular}{lcc}
\hline $\begin{array}{c}\text { Beban } \\
\text { Kerja }\end{array}$ & $\begin{array}{c}\text { Frekuensi } \\
(\mathbf{F})\end{array}$ & $\begin{array}{c}\text { Persentase } \\
(\boldsymbol{\%})\end{array}$ \\
\hline Rendah & 1 & 1,7 \\
\hline Tinggi & 57 & 98,3 \\
\hline
\end{tabular}


Berdasarkan tabel 4.3 didapatkan hasil bahwa hampir seluruh responden memiliki beban kerja tinggi sebanyak 57 responden $(98,3 \%)$ dan sebagian kecil responden memiliki beban kerja rendah sebanyak 1 responden $(1,7 \%)$.

Berdasarkan tabel 1 didapatkan hasil bahwa sebagian besar responden pada karakteristik mental seluruhnya berada pada kategori tinggi sebanyak 58 responden $(100,0 \%)$, pada kategori fisik mendominasi hasil tinggi sebanyak 57 responden $(98,3 \%)$ dan sebagian kecil responden dengan hasil rendah sebanyak 1 responden $(1,7 \%)$, pada kategori waktu mendominasi dengan hasil tinggi sebanyak 57 responden $(98,3 \%)$ serta yang memiliki persentasi rendah sebanyak 1 responden dengan persentase $(1,7 \%)$. Penelitian ini sejalan dengan penelitian yang telah dilakukan di RSUD Cianjur, bahwa sebagian besar responden pada tingkat beban kerja mental yaitu tinggi dengan presentase $70,1 \%$, serta memiliki beban kerja fisik yang tinggi juga dengan presentase 96,2\% (Marmi \& Prihatiningsih, 2015).

Penelitian ini sejalan dengan penelitian yang dilakuakn oleh Budiawan pada tahun 2015, bahwa sebagain besar responden memiliki tingkat beban kerja pada pekerjaannya tinggi sebanyak 73 orang dengan presentase $73,9 \%$. Penelitian ini berbeda dengan penelitian yang dilakukan di Rumah Sakit Islam, bahwa sebagian besar responden memiliki beban kerja yang sedang yaitu sebanyak 43 orang dengan presentase $81,70 \%$ (Suryani \& Wulandari 2009). Tinggi atau rendahnya tingkat beban kerja pada suatu pekerjaan perawat dapat mempengaruhi patient safety. Hal ini didukung dengan penelitian yang dilakukan oleh Manuho, Warouw dan Hamel pada tahun 2015, bahwa sebagian besar responden memiliki tingkat beban kerja yang rendah yaitu sebanyak $56,25 \%$, hal ini dapat terjadi karena beban kerja perawat bedabeda, dapat dipengaruhi oleh tempat keja ataupun dari banyaknya pasien yang dirawatnya.

Berdasarkan tabel 2 di dapatkan hasil bahwa hampir seluruh respoden memiliki beban kerja tinggi sebanyak 57 responden $(98,3 \%)$ dan responden yang memiliki beban kerja rendah sebanyak 1 responden (1,7\%). Sebagian besar pada penelitian ini mendominasi pendidikan S1 Ners sebanyak 21 responden $(36,2 \%)$, D3 sebanyak 19 responden dengan persentase $(32,8 \%)$, S1 sebamyak 18 responden $(31,0 \%)$. Penelitian ini sejalan dengan penelitian yang dilakukan oleh Satria, Sidin \& Noor pada tahun 2013, bahwa sebagian besar responden yang memiliki beban kerja tinggi adalah Ners yaitu sebanyak 39 orang $(60,9 \%)$. Namun berbeda dengan penelitian yang telah dilakukan oleh sebagian besar responden yang memiliki beban kerja tinggi yaitu pada pendidikan D3 yaitu sebanyak 22 orang dengan presentase $55 \%$ (Sumangando, Rottie \& Lolong, 2017).

Hal ini didukung dengan penelitian yang telah dilakukan oleh Marni dan Prihatiningsih pada tahun 2015, didapatkan hasil penelitian bahwa sebagian besar responden yang memiliki beban kerja tinggi yaitu pada tingkat pendidikan Sarjana sebanyak $33,33 \%$. Hal ini didukung dengan penelitian yang telah dilakukan oleh Manuho, Waruo dan Hamel pada tahun 2015, didapatkan hasil penelitian bahwa hampir seluruh responden yang memiliki beban kerja tinggi yaitu pada tingkat pendidikan D3 sebanyak 13 orang dengan presentase $81,2 \%$. Responden yang sebagian besar berpendidikan D3 juga dapat merupakan faktor yang membantu melancarkan perawat dalam melaksanakan tugasnya karena 
pendidikan D3 yang lebih bersifat praktis menjadikan perawat terbiasa dan terlatih dalam menangani pasien sehingga memungkinkan stressor dapat terkontrol dan tubuh kembali normal, terhindar dari stres kerja.

Beban kerja yang diberikan pada pekerja perlu disesuaikan dengan kemampuan psikis dan fisik pekerja yang bersangkutan. Keadaan perjalanan, waktu perjalanan dari dan ke tempat kerja yang seminimal mungkin dan seaman mungkin berpengaruh terhadap kondisi kesehatan kerja pada umumnya dan kelelahan kerja pada khususnya. Apabila jumlah pasien semakin meningkat seiring dengan perubahan cuaca dan epidemiologi penyakit, maka akan semakin meningkatkan beban kerja perawat sehingga menyebabkan kelelahan kerja yang mempengaruhi performa kerjanya (Maharja, 2015). Beban kerja perawat adalah volume kerja perawat di sebuah unit rumah sakit. Sedangkan volume kerja perawat merupakan waktu yang dibutuhkan untuk menangani pasien per hari. Beban kerja penting diketahui sebagai dasar untuk mengetahui kapasitas kerja perawat agar terdapat keseimbangan antara tenaga perawat dengan beban kerja (Ambarwati \& Lataruva, 2014). Kinerja adalah sesuatu yang dicapai, prestasi yang diperlihatkan dan kemampuan kerja. Kinerja dikatakan tinggi apabila suatu target kerja dapat diselesaikan pada waktu yang tepat atau tidak melampaui batas waktu yang disediakan sedangkan kinerja dikatakan rendah jika diselesaikan melampaui batas waktu yang disediakan atau sama sekali tidak terselesaikan (Manuho, Warouw \& Hamel, 2015).

Beban kerja merupakan suatu kondisi dari pekerjaan dengan uraian tugasnya yang harus diselesaikan pada batas waktu tertentu. Beban kerja dapat dibedakan lebih lanjut ke dalam beban kerja berlebih atau terlalu sedikit 'kuantitatif', yang timbul sebagai akibat dari tugas-tugas yang terlalu banyak atau sedikit diberikan kepada tenaga kerja untuk diselesaikan dalam waktu tertentu, dan beban kerja berlebih atau terlalu sedikit 'kualitatif', yaitu jika orang merasa tidak mampu untuk melakukan suatu tugas, atau tugas tidak menggunakan keterampilan atau potensi dari tenaga kerja. Disamping itu beban kerja berlebih kuantitatif dan kualitatif dapat menimbulkan kebutuhan untuk bekerja selama jumlah jam yang sangat banyak, yang merupakan sumber tambahan darai stres (Sihotang, 2012).

Beban kerja merupakan jumlah rata-rata kegiatan kerja pada waktu tertentu, yang terdiri dari beban kerja fisik, beban kerja psikologis serta waktu kerja. Beban kerja adalah besaran pekerjaan yang harus dipikul oleh suatu jabatan dalam suatu unit organisasi dan merupakan hasil kali antara jumlah pekerjaan dengan waktu. Untuk itu perlu dilakukan upaya penyerasian antara kapasitas kerja, beban kerja dan lingkungan kerja agar diperoleh produktivitas kerja yang optimal. Beban kerja adalah upaya merinci komponen dan target volume pekerjaan dalam satuan waktu dan satuan hasil tertentu. Kinerja adalah penampilan hasil kerja personel baik secara kuantitas maupun kualitas atau organisasi, kinerja tenaga perawat dipengaruhi oleh beberapa faktor, salah satunya adalah beban kerja (Budiawan dkk, 2015).

Perawat sebagai salah satu tenaga kesehatan di rumah sakit memegang peranan penting dalam upaya mencapai tujuan pembangunan kesehatan. Keberhasilan pelayanan kesehatan bergantung pada partisipasi perawat dalam memberikan asuhan keperawatan yang berkualitas bagi pasien. Kinerja perawat adalah hasil dari seluruh aktivitas kerja perawat 
yang merupakan bukti dari pelaksanaan asuhan keperawatan di rumah sakit dengan menggunakan metode proses keperawatan. Kinerja perawat sebenarnya sama dengan kinerja karyawan diperusahaan. Perawat ingin diukur kinerjanya berdasarkan standar obyektif yang terbuka dan dapat dikomunikasikan. Jika perawat diperhatikan dan dihargai sampai penghargaan superior, mereka akan lebih terpacu untuk mencapai kinerjapada tingkat yang lebih tinggi (Bawono \& Nugrahaeni, 2015).

\section{KESIMPULAN}

a. Beban kerja mental sebagian besar responden kategori tingi yaitu sebanyak 58 responden dengan presentase $100 \%$

b. Beban kerja fisik sebagian besar responden kategori tingi yaitu sebanyak 57 responden dengan presentase $98,3 \%$

c. Beban kerja waktu sebagian besar responden kategori tingi yaitu sebanyak 57 responden dengan presentase $98,3 \%$

\section{SARAN}

a. Perlunya perbaikan manajemen keperawatan khususnya pembagian tugas dan waktu bekerja perawat untuk mengurangi beban kerja perawat

b. Perawat perlu menjaga kondisi fisik dan mental dalam memberikan pelayanan keperawatan karena beban kerja yang tinggi

\section{REFERENSI}

Ahmadun, M. (2017). HUBUNGAN BEBAN KERJA PERAWAT DENGAN STRES KERJA DI PUSKESMAS KUALAKAMPAR KABUPATEN PELALAWAN PROVINSI RIAU (Doctoral dissertation, Universitas' Aisyiyah Yogyakarta).
Ambarwati, D. and LATARUVA, E., 2014. Pengaruh beban kerja terhadap stres perawat igd dengan dukungan sosial sebagai variabel moderating (studi pada RSUP Dr. Kariadi Semarang) (Doctoral dissertation, Fakultas Ekonomika dan Bisnis).

Bawono, D.C. and Nugraheni, R., 2015. Analisis Pengaruh Pemberian Insentif, Kepemimpian dan Beban Kerja Terhadap Kinerja Perawat (Studi pada Perawat Ruang RSUD Kota Semarang) (Doctoral dissertation, Fakultas Ekonomika dan Bisnis).

Budiawan, I.N., Suarjana, K. and Wijaya, I.G., 2015. Hubungan kompetensi, motivasi dan beban kerja dengan kinerja perawat pelaksana di Rumah Sakit Jiwa Provinsi Bali. Public Heal Prev Med Arch, 3(2), p.143.

Harianto, D. S. (2001). Tinjauan tingkat risiko low back pain (LBP) pada elemen kerja keperawatan bagian ICU-A Rumah Sakit Pusat Pertamina (RSPP) Jakarta, 2001 (Doctoral dissertation, FKM-UI).

Kalendesang, M.P., Bidjuni, H. and Malara, R., 2017. Hubungan Konflik Peran Ganda Perawat Wanita sebagai Care Giver dengan Stres Kerja di Ruangan Rawat Inap Rumah Sakit Jiwa Prof. Dr. VL Ratumbuysang Provinsi Sulawesi Utara. JURNAL KEPERAWATAN, 5(1).

Kurniawidjaja, L. M., Purnomo, E., Maretti, N., \& Pujiriani, I. (2014). Pengendalian risiko ergonomi kasus low back pain pada perawat di rumah sakit. Majalah Kedokteran Bandung, 46(4), 225233.

Linda, S. E. (2017). Hubungan antara Beban Kerja dan Pendidikan Perawat dengan Kualitas Dokumentasi Keperawatan di Ruang Rawat Inap RS Pelabuhan Jakarta Tahun 2001. Jurnal Kesehatan, 10(2), 22-40. 
Maharja, R., 2015. Analisis Tingkat Kelelahan Kerja Berdasarkan Beban Kerja Fisik Perawat di Instalasi Rawat Inap RSU Haji Surabaya. The Indonesian Journal of Occupational Safety and Health, 4(1), pp.93-102.

Mappanganro, A. (2018). HUBUNGAN BEBAN KERJA PERAWAT DENGAN RESPON TIME PADA PENANGANAN PASIEN DI INSTALASI GAWAT DARURAT RUMAH SAKIT IBNU SINA MAKASSAR. Journal of Islamic Nursing, 3(1), 71-81.

Manuho, E., Warouw, H. and Hamel, R., 2015. Hubungan Beban Kerja Dengan Kinerja Perawat Dalam Pemberian Asuhan Keperawatan Di Instalasi Rawat Inap C1 Rsup Prof. Dr. RD Kandou Manado. JURNAL KEPERAWATAN, 3(2).

Marmi, E.F. and Prihatiningsih, D., 2015. Hubungan Beban Kerja dengan Perilaku Caring Perawat menurut
Persepsi Klien di IGD RS PKU Muhammadiyah Yogyakarta (Doctoral dissertation, $\quad$ STIKES'Aisyiyah Yogyakarta).

Nursalam, M., 2014. Manajemen Keperawatan. Jakarta: Salemba Medika.

Purba, S.I.A., 2018. Hubungan Beban Kerja dengan Kelelahan Kerja pada Perawat di Rumah Sakit Vita Insani Pematangsiantar Tahun 2018.

Sihotang, B.B.P., 2012. Pengaruh Beban Kerja Terhadap Kinerja Perawat Dalam Pelayanan Kegawatdaruratan Di RSUD dr. Djasamen Saragih Pematangsiantar (Master's thesis).

Sumangando, M., Rottie, J. and Lolong, J., 2017. Hubungan Beban Kerja Perawat Dengan Kejadian Low Back Pain (LBP) Pada Perawat Pelaksana di RS Tk. Iii RW Monginsidi Manado. JURNAL KEPERAWATAN, 5(1). 